\title{
Use of a Water-Based Probiotic to Treat Common Gut Pathogens
}

Cornelius C. Dodoo ${ }^{1}$, Paul Stapleton, Abdul W. Basit and Simon Gaisford*

UCL School of Pharmacy, University College London, 29-39 Brunswick Square, London, WC1N 1AX,

UK.

* Corresponding author

Email: s.gaisford@ucl.ac.uk

Tel: +44(0) 20777535863

Fax: +44(0) 20777535942

${ }^{1}$ Present address: School of Pharmacy, University of Health and Allied Sciences, PMB 31, Ho, Volta Region, Ghana 


\section{Abstract}

This work reports the anti-pathogenic effect of a commercially available water-based probiotic suspension, Symprove ${ }^{\mathrm{TM}}$, against three commonly encountered infectious organisms; Escherichia coli, methicillin-resistant Staphylococcus aureus (MRSA) and Shigella sonnei. An isothermal calorimetric assay was used to the monitor growth of the species individually and in binary combinations, while colony plate counting was used to enumerate viable cell numbers. It was observed that all pathogenic species were faster growing than the probiotic bacteria in Symprove ${ }^{\mathrm{TM}}$ after inoculation into growth medium yet in all instances bacterial enumeration at the end of the experiments revealed a significant reduction in the pathogen population compared with the controls. A control population between $10^{8}-10^{9} \mathrm{CFU} / \mathrm{ml}$ was obtained for E. coli and S. sonnei whilst approximately $10^{6} \mathrm{CFU} / \mathrm{ml}$ was obtained for MRSA. Upon co-incubation for 48 hours, no viable counts were obtained for E. coli; a 4-log reduction was obtained for S. sonnei whilst MRSA numbers were down to less than 10 cells $/ \mathrm{ml}$. The results show that Symprove ${ }^{\mathrm{TM}}$ has antipathogenic activity against E. coli, S. sonnei and MRSA.

Keywords: Lactobacilli; MRSA; Shigella sonnei, Escherichia coli; infectious diseases 


\section{Introduction}

Probiotic bacteria, defined as 'live microorganisms that, when administered in adequate amounts, confer a health benefit on the host (Hill et al., 2014) have been known for centuries and have been taken by countless patients. The global market for probiotic products is large and is estimated to reach $\$ 46.5$ bn by 2020 (O'Toole et al., 2017). Drivers for this growth include increasing understanding of probiotic action and greater awareness of the composition of the human microbiome and its role in numerous disease conditions (Sanders, 2009). Recently, a 4-strain aqueous probiotic supplement (Symprove ${ }^{\mathrm{TM}}$, containing Lactobacillus acidophilus NCIMB 30175, Lactobacillus plantarum NCIMB 30173, Lactobacillus rhamnosus NCIMB 30174 and Enterococcus faecium NCIMB 30176) has been shown to reduce clinical symptom severity scores in IBS (Sisson et al., 2014), to reduce abdominal pain scores and significantly reduce constipation, diarrhoea and mucorrhoea in diverticular disease (Kvasnovsky et al., 2017).

Symprove appears to have clinical efficacy in part because its water-based formulation is effective at protecting the probiotic bacteria from the challenges of oral delivery (Fredua-Agyeman and Gaisford, 2015). In-vivo, consumption of water does not trigger production of stomach acid (which is primarily secreted to facilitate digestion of proteins by denaturing them and activating pepsinogen by converting it to pepsin (Smith and Morton, 2010, Wang et al., 2015). Indeed, ingestion of appreciable volumes of water will dilute gastric juice, raising local $\mathrm{pH}$. Without fat, the stomach will empty water into the small intestine rapidly (the half-emptying time in humans is $13 \pm 1$ min (Mudie DM et al., 2014), where local pH rises again (the small intestine $\mathrm{pH}$ gradually increases along its length from ca. 5.6 to 7.4 (Ibekwe et al., 2008). Lactobacilli have been shown to have appreciable acid-tolerance; for instance, L. acidophilus strains remain viable at pH 3.5 (Chou and Weimer, 1999) while L. rhamnosus strains can remain viable for several hours at pH 3 (Succi et al., 2005). When fat is a component of the ingested foodstuff, water empties at the same rate but the fat is retained for a longer period (Chang et al., 1968). 
In addition to potentially ameliorating the clinical symptoms of gut disorders, a further potential application of probiotics is to counter infections caused by pathogenic species and immunomodulation (Fredua-Agyeman et al., 2017, Moens et al., 2019). Intestinal Infectious diseases caused by pathogenic organisms are major causes of mortality in both developed and developing countries (Nomoto, 2005). According to the World Health Organization, diarrheal disease is the second leading cause of death and the leading cause of malnutrition in children under 5 years old. It kills around 525,000 children in that age group, and over 1.7 billion people overall, per year (WHO, 2017). Organisms like Shigella spp., Vibrio cholerae, pathogenic E. coli, Campylobacter spp., and rotavirus are the usual organisms involved in such cases (Nomoto, 2005, O'Ryan et al., 2005). Shigellosis remains a common gastrointestinal disease in developing and industrialized countries. Shigella spp. are etiologic agents of gastrointestinal diseases worldwide and are frequently associated with outbreaks because of their low infectious doses (Kim et al., 2015, BoumgharBourtchai et al., 2008). E. coli generally lives in the gastrointestinal tract as a commensal organism, but in immuno-compromised hosts or where the normal gastrointestinal barriers are breached, $E$. coli can lead to disease states (Kaper et al., 2004). E. coli strains have also been suspected to participate in the pathogenesis of Crohn's disease due to the increased number of coliforms in their faeces, particularly during periods when the disease is active (Darfeuille-Michaud et al., 2004).

Methicillin-resistant Staphylococcus aureus (MRSA) has been involved in an increasing number of outbreaks in food-producing animals and foodstuffs from animal origin. MRSA food poisoning arises as a result of the toxins released by these resistant strains as a result of metabolism. MRSA food poisoning is generally attributed to poor handling of food products (Zhu et al., 2014, Shriver-Lake et al., 2003, Zhu et al., 2015). MRSA has historically been a problem associated with the hospital environment. In recent years, however, there has been an increase in community-acquired MRSA cases (Appelbaum, 2006, French, 2009, Otto, 2012). Many S. aureus infections present as moderately severe infections of the skin or respiratory tract, at other times it may be involved in life- 
threatening conditions, such as necrotising fasciitis or necrotising pneumonia (Otto, 2012, Sikorska and Smoragiewicz, 2013).

The challenge of treating these infectious agents is particularly acute in the context of the growing problem of antibiotic resistance; antibiotics have been around for over 50 years yet nosocomial (hospital acquired) infection rates are not declining and multi-drug resistant bacteria continue to emerge creating a major public health problem as a result (Broeckx et al., 2016, Teughels et al., 2011). MRSA is increasingly becoming resistant to other classes of antibiotics; for instance, it is considered resistant to beta-lactams and there have been reports of resistance to vancomycin as well, posing a significant threat to the treatment of systemic infections like bacteraemia (Appelbaum, 2006). The problem is compounded by the lack of new generation antibiotics in development. The use of probiotics in combating pathogens is attractive because the mechanisms of action, which may include production of bacteriocins or producing harsh environmental conditions, are non-specific and do not target particular cellular pathways. Understanding the role of probiotic species in controlling and reducing pathogen populations is therefore an important stage in optimising clinical use of probiotic products in infection control. The use of probiotics as adjuncts to antibiotic therapy has also been demonstrated with positive outcomes (Sizemore et al., 2012). In this work we report the evaluation of the antipathogenic activity of Symprove against three common infectious pathogens; Escherichia coli, Shigella sonnei and MRSA. Isothermal calorimetry, a technique that has been used previously in the study of bacterial growth kinetics was used here for analysis to provide real-time data on microbial growth kinetics (Said et al., 2014a, Said et al., 2014b, Braissant et al., 2010, Fredua-Agyeman and Gaisford, 2015, Fredua-Agyeman et al., 2017). 


\section{Materials and methods}

\subsection{Microorganisms}

Symprove (original flavour) was supplied by Symprove Ltd (Farnham, UK). The pathogenic species evaluated were Escherichia coli (NCTC 10418), Methicillin-resistant Staphylococcus aureus (NCTC 13373), and Shigella sonnei (ATCC 25931).

\subsection{Growth media and reagents}

Nutrient broth, de Man, Rogosa, and Sharpe (MRS) agar, cooked meat medium and MacConkey agar were purchased from Oxoid Ltd, UK. Glucose was purchased from Sigma-Aldrich, UK and phosphate buffered saline (PBS) tablets were from Fisher Scientific, UK.

\subsection{Verifying the bacterial population of Symprove}

A $100 \mu \mathrm{L}$ aliquot of Symprove was added to $900 \mu \mathrm{L}$ PBS at pH 7.4 and vortexed for $10 \mathrm{~s}$. The suspension was then serially diluted (1 in 10) and plated onto MRS agar. The agar plates were incubated at $37{ }^{\circ} \mathrm{C}$ under anaerobic conditions for 48 hours after which colonies were counted.

\subsection{Culture methods}

To ensure constant growth characteristics of the pathogenic bacterial populations, the pathogenic species were cultivated and stored in frozen aliquots. E. coli was grown on nutrient agar and incubated overnight at $37^{\circ} \mathrm{C}$. A few colonies were then taken and used to inoculate nutrient broth $(7 \mathrm{~mL})$ to create a starter culture that was incubated for 24 hours. Fresh nutrient broth $(99 \mathrm{~mL})$ was inoculated with the starter culture $(1 \mathrm{~mL})$ to create a 1: 100 dilution. This was incubated for a further 24 hours, at which point the bacteria were in the stationary phase. The culture was then mixed using a magnetic stirrer, to ensure an even mixture, and dispensed into falcon tubes. Centrifugation was performed at $9500 \mathrm{rpm}$ and $4{ }^{\circ} \mathrm{C}$ for 10 minutes using a Sigma 3-16KL centrifuge (Germany) to harvest the cells after which the supernatant was removed carefully by suction. The cells were 
washed with PBS and centrifuged at $9500 \mathrm{rpm}$ and $4{ }^{\circ} \mathrm{C}$ for 10 minutes. The supernatant was removed by suction and the washing process repeated. The cells were resuspended in $1 / 4$ Ringer's solution made up with $15 \% \mathrm{v} / \mathrm{v}$ glycerol, acting as a cryo-protectant. The bacterial cultures were mixed continuously using a hotplate stirrer (at $1000 \mathrm{rpm}$ and $37^{\circ} \mathrm{C}$ ) and then dispensed $(1.8 \mathrm{~mL}$ ) aseptically into $2 \mathrm{~mL}$ cryovials (Nunc). Sealed vials were immersed gently into liquid nitrogen for 10 minutes after which the frozen vials were removed and stored in a freezer at $-80^{\circ} \mathrm{C}$. Prior to use, each frozen vial was thawed in a water bath at $40{ }^{\circ} \mathrm{C}$ for 3 minutes. The same growth media and conditions were used for MRSA.

For S. sonnei initial cultivation was conducted on MacConkey agar after which all other parameters were maintained. Post-freezing populations of $10^{6}, 10^{6}$ and $10^{5} \mathrm{CFU} / \mathrm{ml}$ were obtained for E. coli, S. sonnei, and MRSA respectively.

\subsection{Evaluating the antibacterial property of Symprove}

Isothermal calorimetry was used to investigate the antipathogenic properties of Symprove against the pathogens. Power-time curves were recorded for the pathogenic species alone, Symprove alone and pathogenic species co-incubated with Symprove. Data were recorded with a 2277 Thermal Activity Monitor (TAM, TA Instruments Ltd., UK) operated at $37 \pm 0.001{ }^{\circ} \mathrm{C}$. Sterile glass calorimetric ampoules ( $3 \mathrm{~mL}$ volume) were used and were hermetically sealed prior to measurement. Cooked meat medium supplemented with $2 \%$ glucose $(\mathrm{CMMg})$ was used as the growth medium. Frozen vials of the pathogenic species (E. coli $\left(10^{6} \mathrm{CFU} / \mathrm{mL}\right), \mathrm{MRSA}\left(10^{5} \mathrm{CFU} / \mathrm{mL}\right)$, S. sonnei $\left.\left(10^{6} \mathrm{CFU} / \mathrm{mL}\right)\right)$ were used for each experiment. Each ampoule contained sterilised cooked meat medium $(0.3 \mathrm{~g})$ suspended in glucose solution $(2 \% \mathrm{w} / \mathrm{v})$. The volumes used for inoculation were as follows: Symprove, E. coli and S. sonnei $(30 \mu \mathrm{L})$ and MRSA (300 $\mu \mathrm{L})$. 
Prior to commencing data capture, samples were placed into the thermal equilibration position of the calorimeter ( $29 \mathrm{~min}$ ) before being lowered into the measurement position ( $1 \mathrm{~min}$ ); data collection therefore started exactly 30 minutes after inoculation (this was to enable the temperature of the ampoule and that of the calorimeter to be equal). Data were recorded with Digitam 4.1 (1 data point every 10 seconds).

Following calorimetric evaluation, the glass ampoules were opened and viable cell numbers determined via colony counting. E. coli and MRSA were enumerated on nutrient agar plates, $S$. sonnei was enumerated on MacConkey agar and Symprove bacteria were enumerated on MRS agar plates in all instances. Enumeration was performed in triplicate and data are presented as mean \pm sd.

\section{Results and Discussion}

To exert a clinical effect, probiotic supplements must first contain the number of viable bacteria stated on the packaging (Hoa, 2000, Fredua-Agyeman and Gaisford, 2015, Hamilton-Miller, 2002, Hamilton-Miller et al., 2007, Temmerman et al., 2003, de Vos et al., 2010, Huff, 2004, Masco et al., 2005). Enumeration of Symprove yielded an average probiotic population of $4.08 \times 10^{8} \mathrm{CFU} / \mathrm{mL}$. With a recommended dose of $70 \mathrm{~mL}$, the probiotic population per dose was calculated as $2.86 \times 10^{10}$

(Table 1). Quantification of the numbers of individual strains was not conducted here since only the total cell number is stated on the product pack, but the measured viable count matched that on the packet.

Testing the effect of probiotics on pathogens has been conducted previously but most of these tests were done using the agar diffusion method (Karska-Wysocki et al., 2010, Tuo et al., 2013). These tests do not permit assessment of bacterial growth in real-time; they show end-point viability only. 
Here, isothermal calorimetry was used to monitor growth as it provides real-time growth curves; as the number of bacteria increases, so does the power output from the vessel (Said et al., 2015, Fredua-Agyeman and Gaisford, 2015, Braissant et al., 2010, Fredua-Agyeman et al., 2017). When microbes are inoculated into an ampoule with an appropriate culture medium, there is an initial lag period which is dependent on the cell density and age of the cells (Belaich, 1980). The calorimeter, although very sensitive, has a limit of detection of about $10^{5}-10^{6}$ active cells (because one viable cell produces ca. $2 \mathrm{pW}$ and the sensitivity of the TAM is ca. $0.1 \mu \mathrm{W}$ ); any cell density below this limit contributes to the lag time (Gaisford et al., 2009, Braissant et al., 2010, Kabanova et al., 2009). With bacterial metabolism, and utilisation of the nutrients in the medium for growth, cell density increases resulting in an increasing power output. The power signal will vary in proportion to metabolic activity and typically a series of peaks and troughs will be seen, reflecting sequential utilisation of nutrients. Once nutrients are exhausted, or the environment in the medium is toxic, the power signal returns to zero. It is important to note here that because power is a rate value, cells that are in a state of stasis and cells that are non-viable cannot be differentiated by calorimetry, because both will give zero power. Microbes have been shown to be viable over many hours even after the stationary phase of growth and this has been confirmed by viable counts being obtained after plating out at such periods (Hrenovic, 2009, Stulova et al., 2015, Braissant et al., 2013). Hence, the calorimetric data allow visual assessment of the rate of growth, but quantification of viable cell numbers at the end of the growth phases must be undertaken by colony counting. It is also important to recognise that because power is a ubiquitous property, it is not possible to analyse calorimetric data and know unequivocally which organisms are contributing to the measured power at any point. Interpretation must be performed qualitatively; the growth profiles of the individual species are measured and compared with the data from binary populations.

We discussed the use of isothermal calorimetry in a previous study of Lactobacilli co-inoculated with Clostridium difficile (Fredua-Agyeman and Gaisford, 2015). In that study, co- inoculated of C. diff 
with Lactobacilli resulted in complete eradication of the pathogen; mechanistically, it was shown that the primary cause of antipathogenic activity was the reduction in $\mathrm{pH}$ caused by proliferation of the probiotic (Lactobacilli produce lactic acid as a by-product of metabolism). However, one issue with that study was that the probiotic was a faster-growing species than the $C$. diff, and so because experiments were performed in sealed ampoules it was possible that the probiotic was effective only because it utilised nutrients and poisoned the environment before the pathogen could respond. Here, all three pathogens grow faster that the probiotic and so this limitation is removed.

The data in Figure 1 show the power-time data for Symprove and E. coli alone and in combination. Several observations are apparent; (i) as noted above, the pathogen grows faster than the probiotics (ii) growth of both the pathogen and probiotics are seen in mixed culture and (iii) the growth curves of all species are altered in mixed culture. At first glance, the data suggest that the probiotic species do not show anti-pathogenic activity against $E$. coli. The colony count data, however, allow greater interpretation (Figure 2). 24h after inoculation E. coli numbers reduced from $10^{9} \mathrm{cfu} / \mathrm{mL}$ when grown alone to $10^{7} \mathrm{cfu} / \mathrm{mL}$ when grown in co-culture while Symprove ${ }^{\mathrm{TM}}$ numbers decreased from $10^{9}$ $\mathrm{cfu} / \mathrm{mL}$ when grown alone to $1 \times 10^{7} \mathrm{cfu} / \mathrm{mL}$ when grown in co-culture. In other words, growth of all species was reduced in co-culture, as indicated in the power-time data, but the reduction was greater for the pathogen. Cell counts at $48 \mathrm{~h}$ post-inoculation showed an increase in Symprove numbers (to $10^{9} \mathrm{cfu} / \mathrm{mL}$ ) and a total absence of E. coli. Symprove can therefore be said to be antipathogenic against E. coli.

It is interesting that, in the closed environment of the calorimetric ampoule, the bacteria in Symprove are able to grow after proliferation of $E$. coli given that the pathogen is likely to have utilised the nutrients available in the growth medium. This suggests that the polysaccharide carbohydrates from the malted barley present in the Symprove suspension may be acting as a prebiotic nutrient source for the probiotic bacteria. In order to digest dietary carbohydrates gut 
bacteria must express carbohydrate-active enzymes (CAZymes) to catalyse the breakdown of polysaccharides to fermentable monosaccharides. A recent review of the carbohydrate-digestive capacity of common gut bacteria species showed that firmicutes (to which Lactobacilli spp. belong) expressed significantly more CAZymes that proteobacteria (to which E. coli species belong), (EI Kaoutari et al., 2013). The data also show that $E$. coli are not in themselves capable of modifying their environment after growth such that it becomes toxic to the probiotic species, but that the probiotic species can. The proposed mechanisms of probiotic activity include the release of chemicals or substances with antibacterial activity, competition for adhesion sites and available nutrients, and the production of acids which make the milieu unfavourable for pathogenic bacterial growth (Sanders, 2009, Govender et al., 2014, Verna and Lucak, 2010). Since E. coli generally adapts well to acidic environments (Benjamin and Datta, 1995), the release of acid by the probiotic may not be the primary cause for the complete elimination of viable E. coli cells; this leaves the release of antibacterial metabolites as a probable cause for results obtained.

Figure 3 shows the calorimetric data for Symprove and MRSA. The trends and interpretation are similar to that described above for E. Coli; the pathogen grows first and remains viable after $24 \mathrm{~h}$ but is almost completely eradicated after $48 \mathrm{~h}$, once the probiotic has flourished, Figure 4 . The colony count for MRSA at $48 \mathrm{~h}$ was not absolutely zero, but there was an 8-log reduction in viable cell numbers and the final concentration was below that deemed clinically infectious. Antagonistic effects of probiotics on MRSA have been mainly attributed to bacteriocin-like inhibitors and/or production of organic acids (Sikorska and Smoragiewicz, 2013, Brachkova et al., 2010, Jabbar et al., 2011, Karska-Wysocki et al., 2010). The effect of organic acids on MRSA has been reported, with pH values between 4.6 to 10 suggested as optimal for S. aureus growth (Charlier et al., 2009, Tatini et al., 1971, Minor and Marth, 1970). Minor and Marth (1970) observed a 99\% reduction in bacterial numbers as a result of acidifying milk with lactic acid. The degree of acidification by a starter culture 
has been linked to its degree of inhibition (Charlier et al., 2009). Jabbar et al. (2011) also reported the potential of culture supernatants of L. acidophilus in preventing MRSA biofilm formation.

Figure 5 shows the calorimetric data for Symprove and S. sonnei and again similar interpretation can be made as above. In this case, however, colony counts at 48 h (Figure 6 ) show that the pathogen has not been completely eradicated; its numbers reduced to $10^{4} \mathrm{cfu} / \mathrm{mL}$. However, in evaluating antimicrobial effects, a 3-log reduction is considered to be a significant reduction (Usacheva et al., 2014, Heffernan et al., 2013, Koh et al., 2013, Sun et al., 2014). S. sonnei has been reported to be very susceptible to acidic environments. The antibacterial property of probiotic culture supernatants has been lost when the $\mathrm{pH}$ of the media was restored to a near neutral pH (Zhang et al., 2011, Zhang et al., 2012). The antagonistic effect obtained here could, therefore, be as a result of change in $\mathrm{pH}$. $L$. rhamnosus, L. acidophilus and L. plantarum have been reported to demonstrate varying degrees of antibacterial activity against S. sonnei and E. coli (Tuo et al., 2013, Hutt et al., 2006, Apella et al., 1992). It was hence, not surprising for a formulation containing such probiotic organisms to demonstrate antagonistic activity against these pathogens. Nevertheless, S. sonnei is a very infective organism with as little as 10 organisms capable of causing disease (Hochstein, 2013). Considering that a single probiotic inoculation was used in this instance, continuous dosing could possibly result in complete elimination of $S$. sonnei viability, and the results also show that calorimetric analysis indicate qualitatively the difficulty in eradicating pathogenic species.

\section{Conclusion}

It has been demonstrated that Symprove has some antipathogenic activity against E. coli, S. sonnei, and MRSA even though in all cases the pathogen was the faster-growing species. The results indicate that ingestion of probiotic supplements, and effective integration and proliferation of probiotic 
species in the gut, may be a new clinical option in treating gut infections. Importantly, when probiotics are used to control infections, the genetic diversity of the pathogenic population is retained, despite the reduction in total bacterial numbers, meaning that probiotic treatment will not drive the creation of antimicrobial-resistant strains. Investigations will be carried out in future using more complicated models with greater resemblance to the human gastrointestinal tract to study these conditions.

\section{Acknowledgements:}

CD thanks the Commonwealth Scholarship Commission in the UK for a PhD scholarship. 


\section{References}

APELLA, M. C., GONZALEZ, S. N., NADER DE MADAS, M. E., ROMERO, N. \& OLIVER, G. 1992. In vitro studies on the inhibition of the growth of Shigella sonnei by Lactobacillus casei and Lact. acidophilus. Journal of Applied Bacteriology, 73, 480-483.

APPELBAUM, P. C. 2006. MRSA--the tip of the iceberg. Clin Microbiol Infect, 12 Suppl 2, 3-10.

BELAICH, J. P. 1980. Growth and metabolism in bacteria. In: BEEZER, A. E. (ed.) Biological microcalorimetry. London: Academic press.

BENJAMIN, M. M. \& DATTA, A. R. 1995. Acid tolerance of enterohemorrhagic Escherichia coli. Applied and Environmental Microbiology, 61, 1669 - 1672.

BOUMGHAR-BOURTCHAI, L., MARIANI-KURKDJIAN, P., BINGEN, E., FILLIOL, I., DHALLUIN, A., IFRANE, S. A., WEILL, F. \& LECLERCQ, R. 2008. Macrolide-Resistant Shigella sonnei. Emerging Infectious Diseases, 14, 1297 - 1299.

BRACHKOVA, M. I., DUARTE, M. A. \& PINTO, J. F. 2010. Preservation of viability and antibacterial activity of Lactobacillus spp. in calcium alginate beads. Eur J Pharm Sci, 41, 589-96.

BRAISSANT, O., BONKAT, G., WIRZ, D. \& BACHMANN, A. 2013. Microbial growth and isothermal microcalorimetry: Growth models and their application to microcalorimetric data. Thermochimica Acta, 555, 64-71.

BRAISSANT, O., WIRZ, D., GOPFERT, B. \& DANIELS, A. U. 2010. Use of isothermal microcalorimetry to monitor microbial activities. FEMS Microbiol Lett, 303, 1-8.

BROECKX, G., VANDENHEUVEL, D., CLAES, I. J. J., LEBEER, S. \& KIEKENS, F. 2016. Drying techniques of probiotic bacteria as an important step towards the development of novel pharmabiotics. International Journal of Pharmaceutics, 505, 303 - 318.

CHANG, C. A., MCKENNA, R. D. \& BECK, I. T. 1968. Gastric emptying rate of the water and fat phases of a mixed test meal in man. Gut, 9, 420-424.

CHARLIER, C., CRETENET, M., EVEN, S. \& LE LOIR, Y. 2009. Interactions between Staphylococcus aureus and lactic acid bacteria: an old story with new perspectives. Int J Food Microbiol, 131, 30-9.

CHOU, L.-S. \& WEIMER, B. 1999. Isolation and characterisation of acid- and bile-tolerant isolates from strains of Lactobacillus acidophilus. J Dairy Sci, 82, 23-31.

DARFEUILLE-MICHAUD, A., BOUDEAU, J., BULOIS, P., NEUT, C., GLASSER, A.-L., BARNICH, N., BRINGER, M.-A., SWIDSINSKI, A., BEAUGERIE, L. \& COLOMBEL, J.-F. 2004. High prevalence of adherent-invasive Escherichia coli associated with ileal mucosa in Crohn's disease. Gastroenterology, 127, 412-421.

DE VOS, P., FAAS, M. M., SPASOJEVIC, M. \& SIKKEMA, J. 2010. Encapsulation for preservation of functionality and targeted delivery of bioactive food components. International Dairy Journal, 20, 292-302.

EL KAOUTARI, A., ARMOUGOM, F., LEROY, Q., VIALETTES, B., MILLION, M., RAOULT, D. \& HENRISSAT, B. 2013. Development and validation of a microarray for the investigation of the CAZymes encoded by the human gut microbiome. PLoS One, 8, e84033.

FREDUA-AGYEMAN, M. \& GAISFORD, S. 2015. Comparative survival of commercial probiotic formulations: tests in biorelevant gastric fluids and real-time measurements using microcalorimetry. Benef Microbes, 6, 141-51. 
FREDUA-AGYEMAN, M., STAPLETON, P., BASIT, A. W., BEEZER, A. E. \& GAISFORD, S. 2017. In vitro inhibition of Clostridium difficile by commercial probiotics: A microcalorimetric study. Int J Pharm, 517, 96-103.

FRENCH, G. L. 2009. Methods for screening for methicillin-resistant Staphylococcus aureus carriage. Clin Microbiol Infect, 15, 10 - 16.

GAISFORD, S., BEEZER, A. E., BISHOP, A. H., WALKER, M. \& PARSONS, D. 2009. An in vitro method for the quantitative determination of the antimicrobial efficacy of silvercontaining wound dressings. Int J Pharm, 366, 111-6.

GOVENDER, M., CHOONARA, Y. E., KUMAR, P., DU TOIT, L. C., VAN VUUREN, S. \& PILLAY, V. 2014. A review of the advancements in probiotic delivery: Conventional vs. nonconventional formulations for intestinal flora supplementation. AAPS PharmSciTech, $15,29-43$.

HAMILTON-MILLER, J. M. T., SHAH, S. \& WINKLER, J. T. 2007. Public health issues arising from microbiological and labelling quality of foods and supplements containing probiotic microorganisms. Public Health Nutrition, 2.

HAMILTON-MILLER, J. M. T., SHAH, S. 2002. Deficiencies in microbiological quality and labelling of probiotic supplements. International Journal of Food Microbiology, 72, $175-176$.

HEFFERNAN, R., SEMIÃO, A. J. C., DESMOND, P., CAO, H., SAFARI, A., HABIMANA, O. \& CASEY, E. 2013. Disinfection of a polyamide nanofiltration membrane using ethanol. Journal of Membrane Science, 448, 170-179.

HILL, C., GUARNER, F., REID, G., G.R., G., MERENSTEIN, D. J., POT, B., MORELLI, L., CANANI, R. B., FLINT, H. J., SALMINEN, S., CALDER, P. C. \& SANDERS, M. E. 2014. The international scientific association for probiotics and prebiotics consensus statement on the scope and appropriate use of the term probiotic. Rev Gastroenterol Hepatol 11, 506-514.

HOA, N. T., BACCIGALUPI, L., HUXHAM, A., SMERTENKO, A., VAN, P. H., AMMENDOLA, S., RICCA, E., CUTTING, S. M. 2000. Characterization of Bacillus species used for oral bacteriotherapy and bacterioprophylaxis of gastrointestinal disorders. Applied and Environmental Microbiology, 66, 5241-5247.

HOCHSTEIN, L. H. 2013. Simultaneous Infection with Shigella sonnei and Vibrio cholerae in a young child. Clinical Laboratory Science, 26, 165 - 170.

HRENOVIC, J. T. I., T. 2009. Survival of Escherichia coli and Acinetobacter junii at various concentrations of sodium chloride. EurAsian Journal of BioSciences, 3, 144- 151.

HUFF, B. A. 2004. "Probiotics" might not be what they seem Canadian Family Physician, 50, 583- 587.

HUTT, P., SHCHEPETOVA, J., LOIVUKENE, K., KULLISAAR, T. \& MIKELSAAR, M. 2006. Antagonistic activity of probiotic lactobacilli and bifidobacteria against entero- and uropathogens. J Appl Microbiol, 100, 1324-32.

IBEKWE, V. C., KHELA, M. K., EVANS, D. F. \& BASIT, A. W. 2008. A new concept in colonic drug targeting: a combined $\mathrm{pH}$-responsive and bacterially-triggered drug delivery technology. Aliment Pharmacol Ther, 28, 911-6.

JABBAR, H., HALA, F. \& RADEEF, M. 2011. Capability of Lactobacillus acidophilus supernatant to inhibit production of lipase from methicillin-resistant Staphylococcus aureus. J. of university of anbar for pure science, 5, 1-5. 
KABANOVA, N., KAZARJAN, A., STULOVA, I. \& VILU, R. 2009. Microcalorimetric study of growth of Lactococcus lactis IL1403 at different glucose concentrations in broth. Thermochimica Acta, 496, 87-92.

KAPER, J. B., NATARO, J. P. \& MOBLEY, H. L. 2004. Pathogenic Escherichia coli. Nat Rev Microbiol, 2, 123-40.

KARSKA-WYSOCKI, B., BAZO, M. \& SMORAGIEWICZ, W. 2010. Antibacterial activity of Lactobacillus acidophilus and Lactobacillus casei against methicillin-resistant Staphylococcus aureus (MRSA). Microbiol Res, 165, 674-86.

KIM, J. S., KIM, J. J., KIM, S. J., JEON, S. E., SEO, K. Y., CHOI, J. K., KIM, N. O., HONG, S., CHUNG, G. T., YOO, C. K., KIM, Y. T., CHEUN, H. I., BAE, G. R., YEO, Y. H., HA, G. J., CHOI, M. S., KANG, S. J. \& KIM, J. 2015. Outbreak of Ciprofloxacin-Resistant Shigella sonnei Associated with Travel to Vietnam, Republic of Korea. Emerg Infect Dis, 21, 1247-50.

KOH, J. J., QIU, S., ZOU, H., LAKSHMINARAYANAN, R., LI, J., ZHOU, X., TANG, C., SARASWATHI, P., VERMA, C., TAN, D. T., TAN, A. L., LIU, S. \& BEUERMAN, R. W. 2013. Rapid bactericidal action of alpha-mangostin against MRSA as an outcome of membrane targeting. Biochim Biophys Acta, 1828, 834-44.

KVASNOVSKY, C. L., BJARNASON, I., DONALDSON, A. N., SHERWOOD, R. A. \& PAPAGRIGORIADIS, S. 2017. A randomized double-blind placebo-controlled trial of a multi-strain probiotic in treatment of symptomatic uncomplicated diverticular disease. Inflammopharmacology, 25, 499-509.

MASCO, L., HUYS, G., DE BRANDT, E., TEMMERMAN, R. \& SWINGS, J. 2005. Culturedependent and culture-independent qualitative analysis of probiotic products claimed to contain bifidobacteria. International Journal of Food Microbiology, 102, 221- 230.

MINOR, T. E. \& MARTH, E. H. 1970. Growth of Staphylococcus aureus in acidifed pasteurized milk. J. Milk Food Technol, 33, 516-520.

MOENS, F., VAN DEN ABBEELE, P., BASIT, A. W., DODOO, C., CHATTERJEE, R., SMITH, B. \& GAISFORD, S. 2018. A four-strain probiotic exerts positive immunomodulatory effects by enhancing colonic butyrate production in vitro. Int J Pharm 555 (2019) 110.

MUDIE DM, M. K., HOAD CL, , PRITCHARD, S. E., GARNETT, M. C., AMIDON, G. L., GOWLAND, P. A., SPILLER, R. C., AMIDON, G. E. \& L., M. 2014. Quantification of gastrointestinal liquid volumes and distribution following a $240 \mathrm{~mL}$ dose of water in the fasted state. Mol Pharm 11, 3039-3047.

NOMOTO, K. 2005. Prevention of infections by probiotics. J Biosci Bioeng, 100, 583-92.

O'TOOLE, P. W., MARCHESI, J. R. \& HILL, C. 2017. Next-generation probiotics: the spectrum from probiotics to live biotherapeutics. Nat Microbiol, 2, 17057.

O'RYAN, M., PRADO, V. \& PICKERING, L. K. 2005. A millennium update on pediatric diarrheal illness in the developing world. Seminars in Pediatric Infectious Diseases, 16, 125136.

OTTO, M. 2012. MRSA virulence and spread. Cell Microbiol, 14, 1513-21.

SAID, J., DODOO, C. C., WALKER, M., PARSONS, D., STAPLETON, P., BEEZER, A. E. \& GAISFORD, S. 2014a. An in vitro test of the efficacy of silver-containing wound dressings against Staphylococcus aureus and Pseudomonas aeruginosa in simulated wound fluid. International Journal of Pharmaceutics, 462, 123-128. 
SAID, J., WALKER, M., PARSONS, D., STAPLETON, P., BEEZER, A. E. \& GAISFORD, S. 2014b. An in vitro test of the efficacy of an anti-biofilm wound dressing. Int J Pharm, 474, 17781.

SAID, J., WALKER, M., PARSONS, D., STAPLETON, P., BEEZER, A. E. \& GAISFORD, S. 2015. Development of a flow system for studying biofilm formation on medical devices with microcalorimetry. Methods, 76, 35-40.

SANDERS, M. E. 2009. How do we know when something called "probiotic" is really a probiotic? A guideline for consumers and Health care professionals. Functional Food Reviews, 1, 3 - 12.

SHRIVER-LAKE, L. C., SHUBIN, Y. S. \& LIGLER, F. S. 2003. Detection of Staphylococcal Enterotoxin B in Spiked Food Samples. Journal of Food Protection, 66, 1851-1856.

SIKORSKA, H. \& SMORAGIEWICZ, W. 2013. Role of probiotics in the prevention and treatment of meticillin-resistant Staphylococcus aureus infections. International Journal of Antimicrobial Agents, 42, 465-481.

SISSON, G., AYIS, S., SHERWOOD, R. A. \& BJARNASON, I. 2014. Randomised clinical trial: A liquid multi-strain probiotic vs. placebo in the irritable bowel syndrome--a 12 week double-blind study. Aliment Pharmacol Ther, 40, 51-62.

SIZEMORE, E. N., RIVAS, K. M., VALDES, J. \& CABALLERO, J. 2012. Enteral vancomycin and probiotic use for methicillin-resistant Staphylococcus aureus antibiotic-associated diarrhoea. BMJ Case Rep, 2012.

SMITH, M. E. \& MORTON, D. G. 2010. The stomach: Basic functions. In, (2nd Ed), , ISBN 9780-7020-3367-4 (2010). The Digestive System 2nd ed.: Churchill Livingstone.

STULOVA, I., KABANOVA, N., KRISCIUNAITE, T., ADAMBERG, K., LAHT, T. M. \& VILU, R. 2015. Microcalorimetric study of the growth of Streptococcus thermophilus in renneted milk. Front Microbiol, 6, 79.

SUCCI, M., TREMONTE, P., REALE, A., SORRENTINO, E., GRAZIA, L., PACIFICO, S. \& COPPOLA, R. 2005. Bile salt and acid tolerance of Lactobacillus rhamnosus strains isolated from Parmigiano Reggiano cheese. FEMS Microbiol Lett, 244, 129-137.

SUN, Y., WANG, L., LI, J., ZHAO, C., ZHAO, J., LIU, M., WANG, S., LU, C., SHANG, G., JIA, Y. \& WEN, A. 2014. Synergistic efficacy of meropenem and rifampicin in a murine model of sepsis caused by multidrug-resistant Acinetobacter baumannii. Eur J Pharmacol, 729, 116-22.

TATINI, S. R., JEZESKI, J. J., OLSON, J. C. J. \& CASMAN, E. P. 1971. Factors influencing the production of staphylococcal enterotoxin A in milk. J. Dairy Sci. , 54, 312-320.

TEMMERMAN, R., POT, B., HUYS, G. \& SWINGS, J. 2003. Identification and antibiotic susceptibility of bacterial isolates from probiotic products. International Journal of Food Microbiology, 81, 1-10.

TEUGHELS, W., LOOZEN, G. \& QUIRYNEN, M. 2011. Do probiotics offer opportunities to manipulate the periodontal oral microbiota? J Clin Periodontol, 38 Suppl 11, 159-77.

TUO, Y., ZHANG, W., ZHANG, L., Al, L., ZHANG, Y., HAN, X. \& YI, H. 2013. Study of probiotic potential of four wild Lactobacillus rhamnosus strains. Anaerobe, 21, 22-7.

USACHEVA, E. A., GRAYES, A., SCHORA, D. \& PETERSON, L. R. 2014. Investigation of tigecycline bactericidal activity: Optimisation of laboratory testing. J Glob Antimicrob Resist, 2, 269-275.

VERNA, E. C. \& LUCAK, S. 2010. Use of probiotics in gastrointestinal disorders: what to recommend? Therapeutic Advances in Gastroenterology, 3, 307319. 
WANG, J., YADAV, V., SMART, A. L., TAJIRI, S. \& BASIT, A. W. 2015. Toward oral delivery of biopharmaceuticals: an assessment of the gastrointestinal stability of 17 peptide drugs. Mol Pharm, 12, 966-73.

WHO 2017. Fact sheet on diarrhoeal disease.

ZHANG, Y., ZHANG, L., DU, M., YI, H., GUO, C., TUO, Y., HAN, X., LI, J., ZHANG, L. \& YANG, L. 2011. Antimicrobial activity against Shigella sonnei and probiotic properties of wild lactobacilli from fermented food. Microbiol Res, 167, 27-31.

ZHANG, Y. C., ZHANG, L. W., MA, W., YI, H. X., YANG, X., DU, M., SHAN, Y. J., HAN, X. \& ZHANG, L. L. 2012. Screening of probiotic lactobacilli for inhibition of Shigella sonnei and the macromolecules involved in inhibition. Anaerobe, 18, 498-503.

ZHU, X., SHEN, L., LIU, J., ZHANG, C. \& GU, Q. 2015. Purification of a Bacteriocin from Lactobacillus plantarum ZJ217 Active Against Methicillin-Resistant Staphylococcus aureus. International Journal of Food Engineering, 11.

ZHU, X., ZHAO, Y., SUN, Y. \& GU, Q. 2014. Purification and characterisation of plantaricin ZJ008, a novel bacteriocin against Staphylococcus spp. from Lactobacillus plantarum ZJ008. Food Chem, 165, 216-23. 
Table 1: Average probiotic enumeration per dose of Symprove $(70 \mathrm{ml})$ after triplicate enumeration.

\begin{tabular}{llllll}
\hline & Test $(\mathrm{CFU} / \mathrm{ml})$ & Average & Average & Expected \\
& & & & & \\
(CFU/dose) & population \\
& & $\mathrm{C}$ & & & \\
(CFU/dose)
\end{tabular}




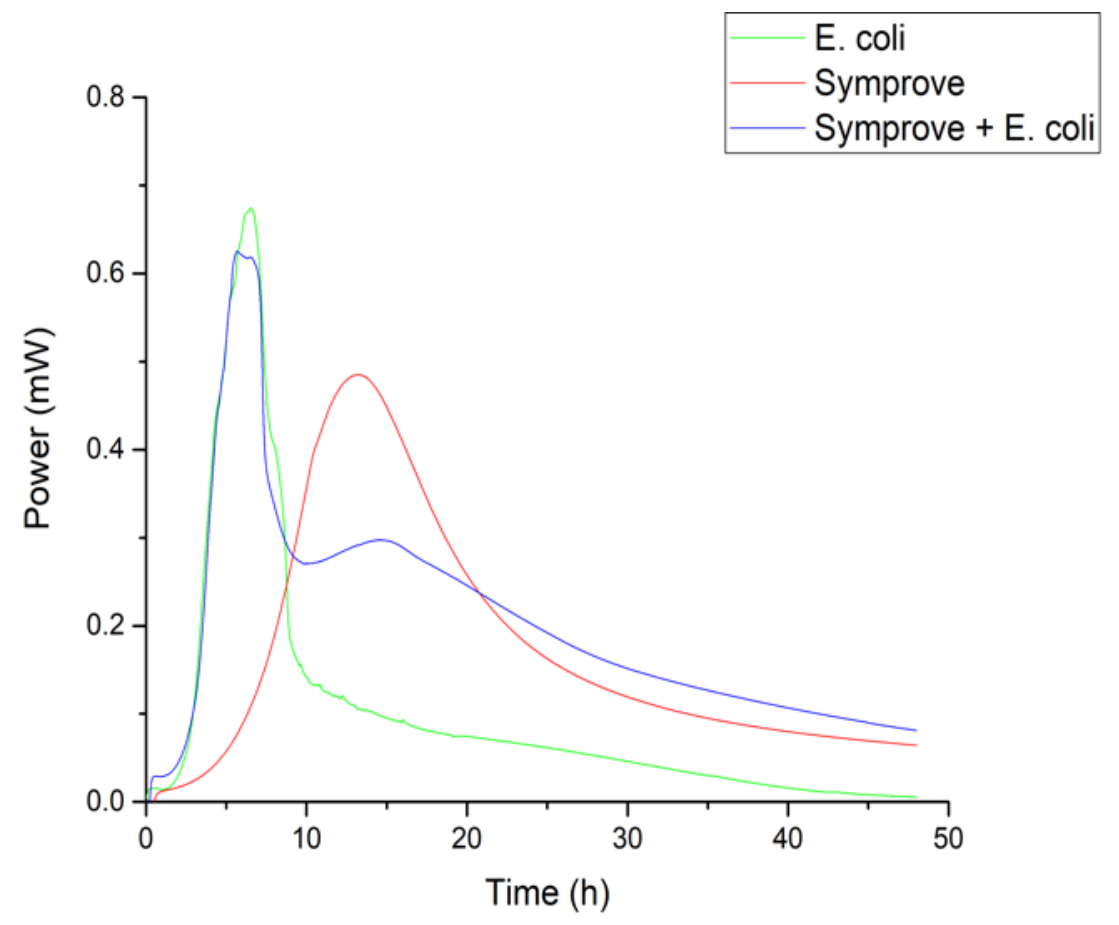

Figure 1: Thermograms obtained after co-incubation of Symprove and E. coli, and their respective controls 


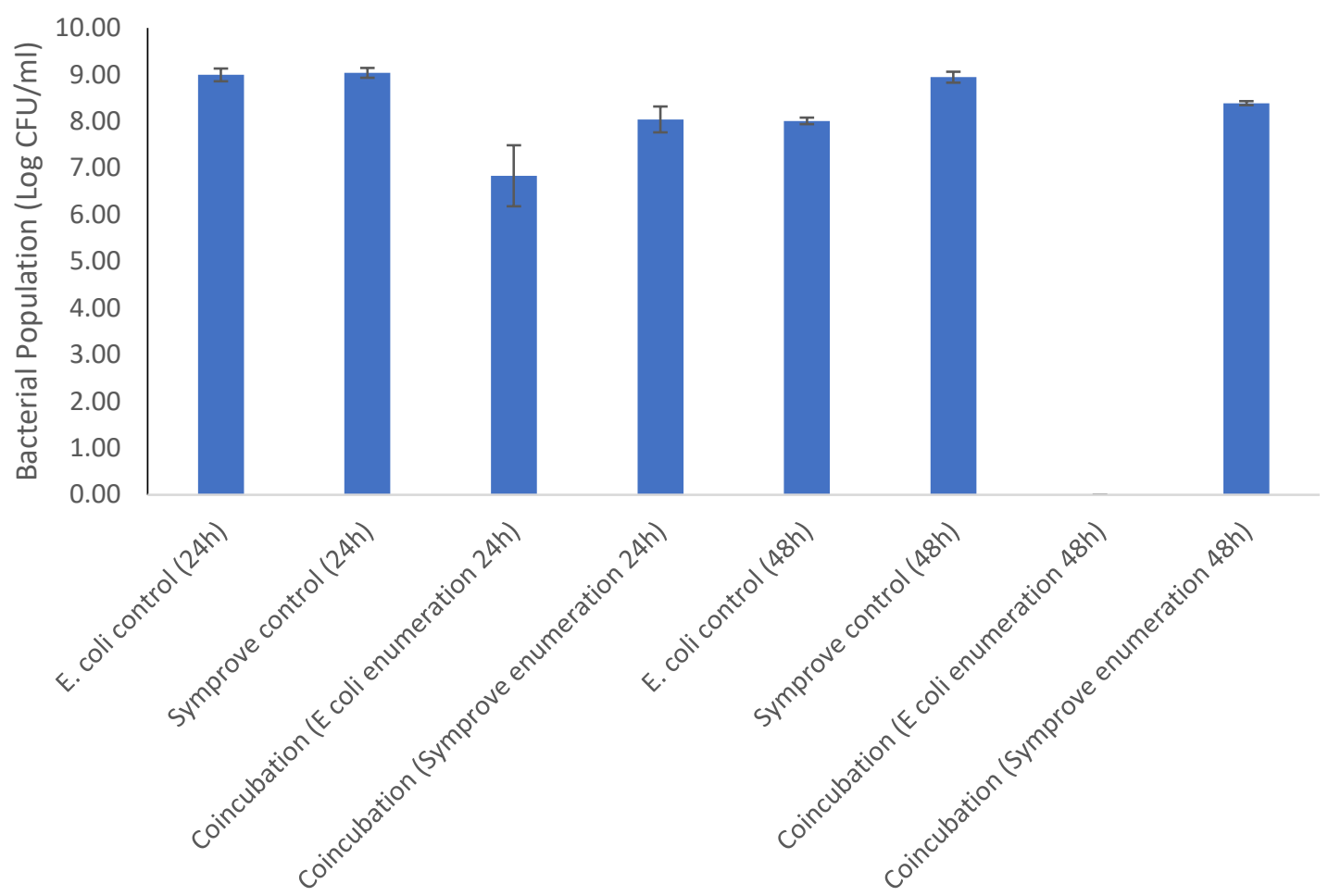

Figure 2: Colony counts at 24 and 48 hours after co-incubation of Symprove and E. coli, and their respective controls 


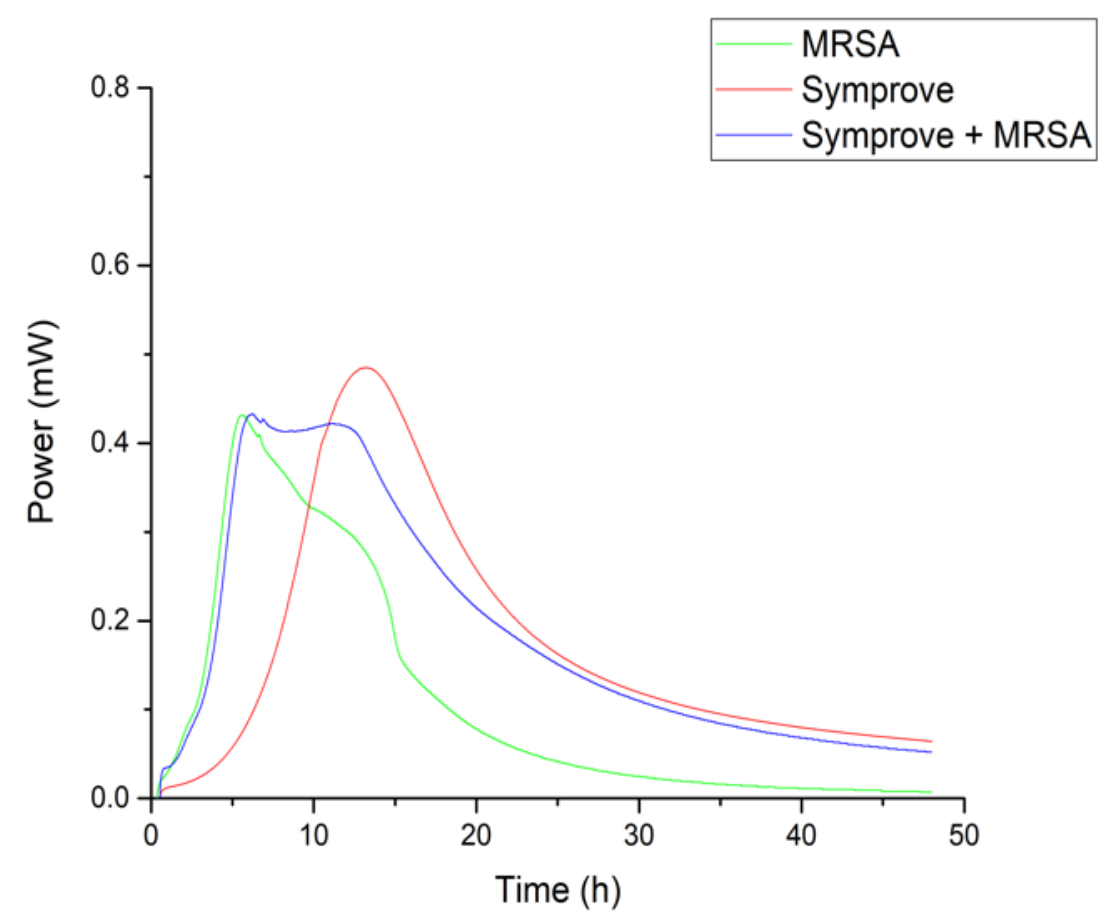

Figure 3: Thermograms obtained after co-incubation of Symprove and MRSA, and their respective controls 


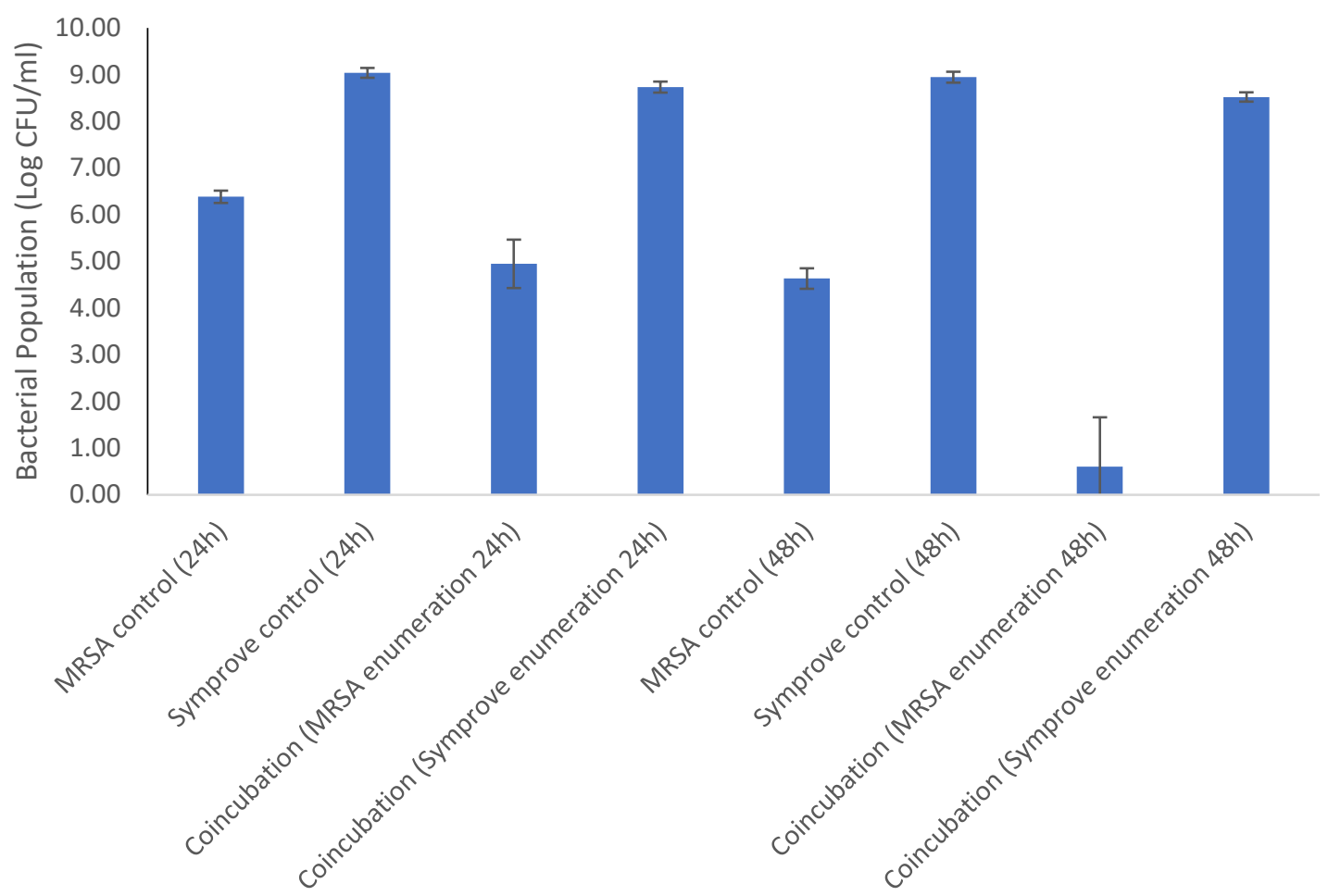

Figure 4: Colony counts at 24 and 48 hours after co-incubation of Symprove and MRSA and their respective controls 


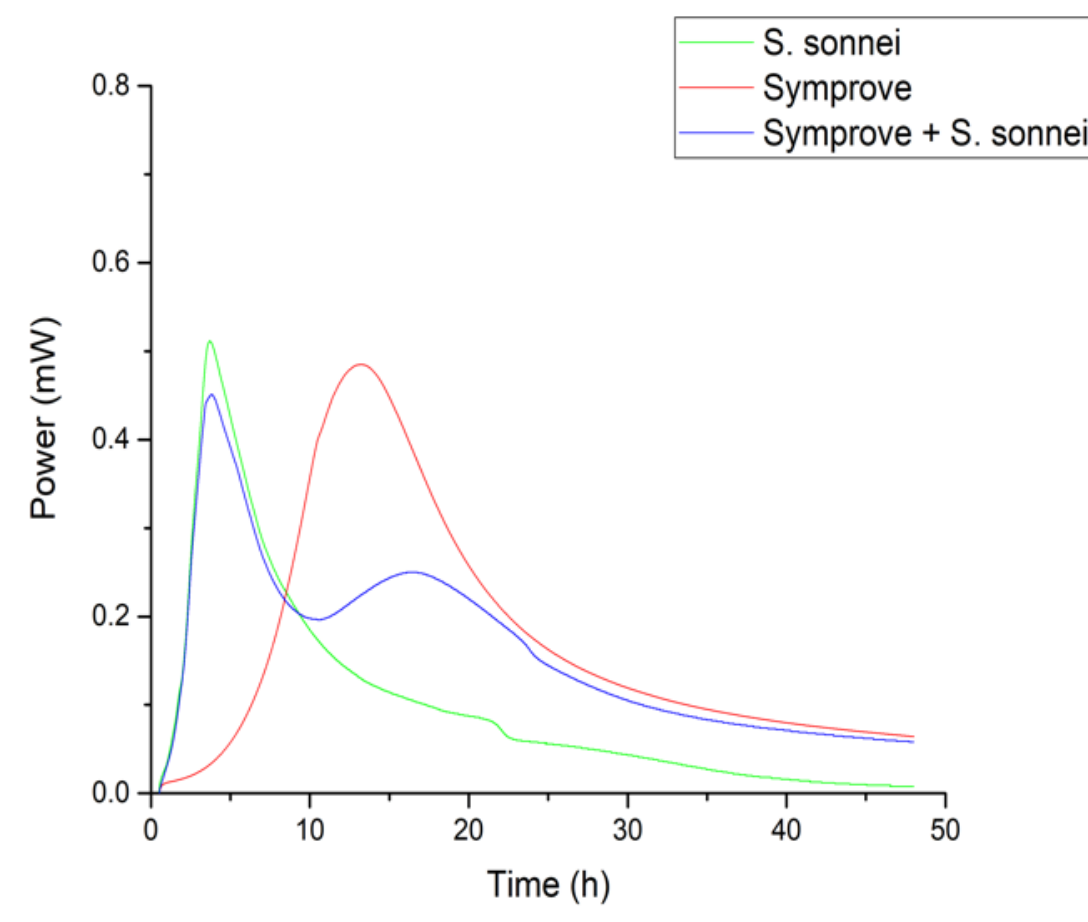

Figure 5: Thermograms obtained after co-incubation of Symprove and S. sonnei, and their respective controls 


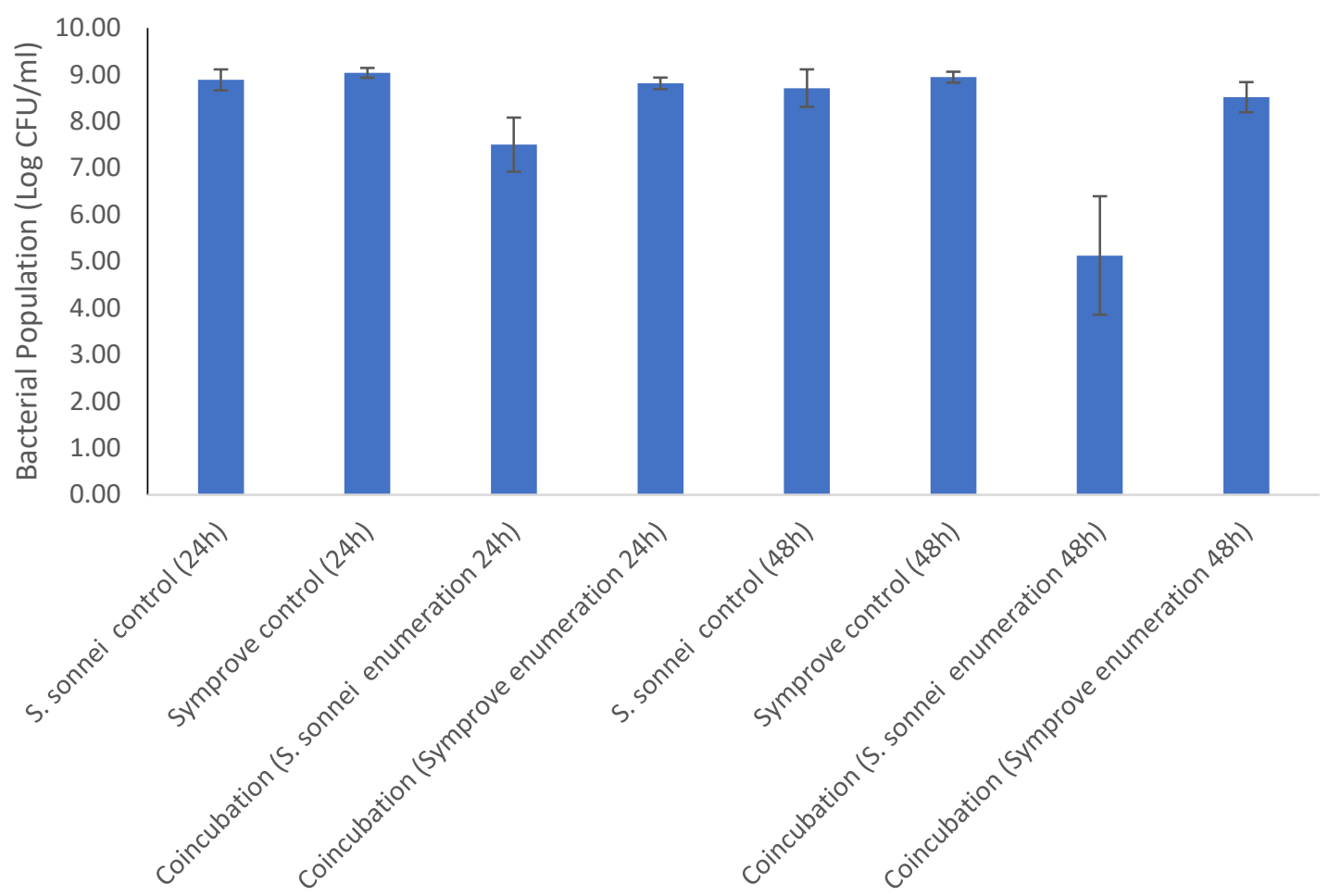

Figure 6: Colony counts at 24 and 48 hours after co-incubation of Symprove and S. sonnei, and their respective controls 